João Barbosa Rodrigues (1842/ 1909) foi lente da Academia Politécnica do Porto (Portugal), professor do Colégio Pedro II. Foi diretor do

Museu Botânico do Amazonas e, de 1890 a 1909 diretor do Jardim Botânico do Rio de Janeiro.

\title{
Hortus fluminensis
}

Hortus fluminensis ou breve notícia sobre as plantas cultivadas no Jardim Botânico do Rio de Janeiro para servir de guia aos visitantes por J. Barbosa Rodrigues, diretor do mesmo jardim - 1893.

\section{Advertência}

Convidado pelo governo provisório da República para dirigir o Jardim Botânico desta capital, deixei o lugar que exercia de diretor do Museu Botânico do Amazonas a 25 de abril de 1890, e a 31 de maio do mesmo ano assumi as funções de meu novo cargo.

Em pequeno período de tempo, compreendi a soma de responsabilidades que me ia pesar sobre os ombros, pois encontrava um estabelecimento sem arquivo, onde estudasse eu sua história, sem pessoal regular, sem biblioteca (nem um livro sobre botânica) e sem herbário onde buscasse auxílio para o trabalho que hoje empreendo.

0 grande parque, coberto de esplêndida vegetação, semelhava uma floresta, cujos exemplares, em promiscuidade, não eram indicados por uma placa, uma etiqueta, um simples sinal que os fizesse conhecidos. Tudo muito agradável à vista, mas, cientificamente, em estado deplorável. Isto foi declarado por uma comissão nomeada pelo governo antes da minha posse.

Como, pois, transformar um simples jardim de recreio quase secular em que os vegetais não podiam ser transplantados para colocá-los por ordem sistemática?

Meu primeiro cuidado foi levantar a planta do
Jardim. Depois tratei de grupar, o mais que pude, pequenos exemplares de espécies congêneres, rarefazendo os grupos antigos em que se encontravam plantas de espécie diferente confundidas. Isso na grande área cultivada. No histórico do estabelecimento, ver-se-á que extensões de terrenos cobertos por mato foram transformados em pontos cultivados.

Penetrando os viveiros, notei aí a mesma desordem científica. Foi necessário separar os vegetais em espécies distintas, colocando-os com método em local apropriado.

Feito esse trabalho preliminar, quer na grande área, quer nos viveiros, dei começo à verificação dos vegetais, trabalho que demanda esforço extraordinário, por tornar-se preciso esperar a época de florescência das plantas para classificá-las.

Assim, consegui saber que na grande área do Jardim não existiam mais que 450 a 500 espécies vegetais, algumas representadas por centenas de exemplares. A rnaior parte exóticas.

Tratei de introduzir plantas do país, principalmente, e isso ver-se-á pelas placas indicativas das mesmas e por este catálogo, que encerrará, no mínimo, três mil espécies.

Não me faltando o auxílio dos poderes públicos, foi no orçamento de 1893 consignada verba para impressão deste trabalho.

Como se sabe, no final desse ano e começo de 1894 , o país esteve convulsionado pela revolta de uma parte da esquadra. O fato levou conseqüências desastrosas a todos os gêneros de atividade nacio- 
nal, de modo a não trabalharem oficinas tipográficas, por falta de pessoal, oficinas que, também, durante meses, não recebiam matéria-prima do estrangeiro para seus trabalhos. Entretanto, não esmoreci e o fruto de meus bons desejos tem o leitor em mãos.

Considerando eu que o catálogo geral só poderia estar terminado em fins de 1895, deliberei fazer a publicação em dois fascículos, contendo o primeiro os vegetais das duas primeiras classes das plantas dicotiledôneas, de De Candole, e o segundo as outras partes.

Aĺ encontrará o leitor, por seus caracteres botânicos, os grandes grupos, classes, famílias, subfamílias, tribos e gêneros, achando-se as espécies pela numeração do catálogo, com indicações de nome botânico e vulgar, de pátria, e informações úteis sobre cada uma.

Trabalho imperfeito é, sem dúvida, este que empreendi; mas penso que melhor não correspondo à confiança do governo, que dando notícia sobre um estabelecimento, que fundado há quase um século, não encontrou quem tornasse conhecidas suas grandes riquezas, atestadas nos vegetais que o público conhecia apenas pelo porte mais ou menos elegante, sem poder deles colher a menor informação, por falta de trabalho que o guiasse. Por esse lado a lacuna vai ser preenchida.

Para maior desenvolvimento, leva este guia, depois do histórico, que com grande trabalho fiz, o regulamento policial do Jardim, assim como no fim da obra relações de todas as plantas, por ordem numérica dos nomes triviais, por ordem alfabética, e seus correspondentes latinos e das famílias, gênerose espécies. Na relação numérica irão indicadas as seções em que estão as plantas com o seu número respectivo, que é sempre o mesmo em todas as duplicatas, disseminadas pelas diversas seções. Um sinal nessa lista indicará as plantas que se trocam ou se fornecem sementes.

Uma planta do Jardim acompanhará o guia no fim da publicação.

Este guia, pois, remediará a falta da plantação sistemática que deveria haver, e foi assim que meIhor consegui guiar o homem da ciência, o estudante e $o$ amador, no labirinto das plantas que se acham espalhadas em todo o perímetro cultivado.

\section{$\mathrm{O}$ autor.}

\section{Jardim Botânico do Rio de Janeiro}

\section{Resumo histórico}

Limitada pelas fraldas verdejantes da Urca, do Corcovado e dos Dois Irmãos, e pelo Oceano Atlân- tico do qual se separa por língua de terra arenosa e com o qual se comunica, por vezes, por estreito canal, se encontra regular superfície de sua água salobra que os habitadores ribeirinhos conheciam outrora pelo nome de çapôpenypau, ou lagoa das raízes chatas $^{1}$. Essa primitiva denominação de capôpeua foi mais tarde transformada em sapopemba.

Al, na margem norte, em 1596, reinando Filipe Ill em Portugal e Espanha e, sendo Francisco Mendonça de Vasconcellos governador do Rio de Janeiro, Diogo de Amorim Soares estabeleceu um engenho de cana sob a invocação de Nossa Senhora da Conceição da Lagoa.

Treze anos mais tarde, em 1609, Diogo de Amorim casou uma de suas filhas com Sebastião Fagundes Varella, e deu-lhe por dote o engenho.

Entretanto, como os terrenos que o estabelecimento ocupava pertenciam à Câmara Municipal do Rio de Janeiro e Amorim só tinha deles o usufruto em virtude de um arrendamento enfitêutico, teve, para fazer transmissão da propriedade a seu genro, de dirigir, a 27 de novembro daquele ano, um requerimento à câmara citada.

Deferido o requerimento, a enfiteuse foi renovada em nome de Sebastião Varella. Nessa data a lagoa passou a chamar-se Lagoa Fagundes Varella.

Cinqüenta anos depois, em 1666, este último, tornando-se bastante rico, vendeu o estabelecimento a Rodrigo de Freitas Mello e Castro. Desde então, a lagoa perdeu o nome de Fagundes Varella para ser conhecida pelo de Lagoa Rodrigo de Freitas, que ainda hoje conserva.

Quando mais tarde, Rodrigo de Freitas retirouse para sua cidade natal de Guimarães, em Portugal, a propriedade passou a dois de seus filhos que a conservaram, bem como seus herdeiros, durante 148 anos.

Invadido Portugal pelos franceses, transportou-se a família real, em 1808, para o Rio de Janeiro. $O$ príncipe regente que foi mais tarde $\mathrm{D}$. João $\mathrm{VI}$, desejoso de criar estabelecimento de valor incontestável, embelezando a colônia que prodigalizara-Ihe hospitalidade, resolveu fundar uma fábrica de pólvora, na altura de sua nova capital.

Ordenou, pois, a seu ministro D. Fernando José de Portugal, marquês de Aguiar, que fizesse desapropriar o engenho de Rodrigo de Freitas, pagando a seus herdeiros a soma de 42:193\$430, a título de indenização. Passou, desde então, o engenho à classe dos próprios nacionais.

Em 13 de maio de 1808, para festejar seu aniversário natalício, o regente promulgou um decreto que mandava estabelecer uma "fábrica de pólvora 
não só para o serviço de S.M. como para uso dos particulares, sob a administração da Junta de Fazenda dos Arsenais, Fábricas e Fundições do Reino."

O primeiro diretor da nova fábrica foi Carlos Antônio Napion, brigadeiro, inspetor da artilharia e das fundições, o qual teve o título de inspetor da Fábrica de Pólvora. Foi ainda nomeado vice-inspetor João Gomes da Silveira Mendonça, depois visconde de Fanado e marquês de Sabará. A chefia da administração foi confiada ao dr. Mariano José Pereira da Fonseca, mais tarde marquês de Maricá.

O general Napion reparou e aumentou os edifícios existentes, a fim de que preenchessem melhor seus fins. Fixou residência na antiga casa de Rodrigo de Freitas. O depósito de salitre, foi estabelecido em dependência próxima, onde se achava a capela de Nossa Senhora da Conceição.

À essa época se liga a construção dos dois grandes portões, de belo estilo, encimados pela coroa real portuguesa e que ainda hoje se podem ver no Jardim, um dando entrada aos viveiros, outro à casa do Salitre, habitação de trabalhadores.

Não contente desse começo e seduzido pela beleza daquele ponto, o príncipe regente, por decreto de 13 de junho do mesmo ano, mandou preparar, perto da casa do inspetor da Fábrica da Pólvora terreno necessário ao estabelecimento de um jardim de aclimação, destinado a introduzir no Brasil a cultura de especiarias das Indias Orientais. Em 11 de outubro, de acordo com o decreto citado, foi nomeado um intendente para o novo jardim que passou a denominar-se Real Horto.

Não foi este, cumpre dizê-lo, o primeiro horto botânico que houve no Brasil. Já em 1796, o mesmo $D$. João $V 1$, por carta régia de 4 de novembro, ordenada ao capitão-general do Pará, D. Francisco de Souza Coutinho, de organizar o horto público de São José, na estrada do mesmo nome. Fundado em 1797, foi seu primeiro diretor o engenheiro agrônomo Grenoullier, emigrado de Caiena. Além de vegetais indígenas, aí foram plantados vários exemplares da flora da Guiana Francesa.

Mas voltemos ao assunto principal destas linhas. Na época da fundação do jardim da Fábrica da Pólvora naufragara em Goa a Fragata Princeza do Brasil. Luiz de Abreu Vieira e Silva, chefe de divisão, e alguns outros, oficiais da tripulação da fragata naufragada, embarcaram no Brigue Conceição e dirigiram-se para o Cabo da Boa Esperança, com destino ao Brasil. Durante a travessia, foram feitos prisioneiros pelos franceses e mandados para a llha de França.

Aíse via o Jardim Gabrielle que possuía gran- de cópia de especiarias, introduzidas por Poivre e Menouvilles.

De acordo com Raphael Bottado de Almeida, senador de Macau, e frei Francisco João da Graça, religioso franciscano, também prisioneiro, Luiz de Abreu, tendo obtido meios de fugir, conseguiu, à força de muitos perigos e grandes sacrifícios, apoderarse de certo número de plantas que pôde embarcar, em caixote, e trazer para o Rio de Janeiro. Chegando, ofereceu-as a D. João, que as fez plantar no seu Real Horto. Foram as primeiras plantas ali introduzidas e sobre elas falaremos adiante.

Em 1810, o marechal Manoel Marques enviou uma nova coleção de plantas e, dois anos depois, em 1812 , sob insistentes pedidos do chefe de divisão Abreu ${ }^{2}$, Raphael Bottado de Almeida, que o auxiliara na fuga, enviou de Macau, por intermédio do capitão-tenente Joaquim Epiphanio de Vasconcellos, comandante do Brigue Vulcano, as primeiras sementes de chá (Thea viridis $L$ ).

Germinando tais sementes, foi iniciada a plantação de chá em grande escala.

Em 1814, D. João fez mesmo vir para o Rio de Janeiro uma colônia chinesa que devia ensinar o processo de preparação do produto.

A cultura do chá desenvolveu-se de tal modo que, por largo tempo, o chá do Jardim, muito estimado no comércio se vendeu em grosso.

Treze anos depois, a indústria chegara a tal ponto que julgou-se conveniente, apesar das perturbações da guerra da independência, tentar a exploração do produto.

Em 4 de setembro de 1837, Manoel Alves Branco, ministro do Império, deu ordem para enviar a Londres algumas amostras de chá. Foram enviadas 100 libras, de diversas marcas que então se preparavam: 34 libras de uchim, 26 de hysson fino, 25 de hysson ordinário e 25 de hysson grosso. Infelizmente a tentativa não foi, afinal, coroada de sucesso.

Entretanto, o Real Horto particular era o passeio favorito do regente que se interessava vivamente pelo seu progresso. Ligava ele tal importância à aclimação e à cultura de especiarias exóticas que, por decisão de 27 de julho de 1809 e aviso de 7 de junho do ano seguinte, prometeu recompensas, medalhas e privilégios aos que cultivassem tais plantas e isentou de direitos de alfândega a importação de material para as fazendas dos que as cultivassem.

Apenas coroado rei do reino de Portugal e Brasil, para dar mais extensão à cultura de plantas úteis no país, aumentou o Real Horto, tornando-o público sob a denominação de Real Jardim Botânico. Foi, então, anexado ao Museu Nacional. 
Tal era a importância da instituição nessa época, que foram chamados para dirigi-la o conselheiro João Severiano Maciel da Costa, depois marquês de Queluz, e João Gomes da Silveira Mendonça ${ }^{3}$, deputado às cortes, o qual primitivamente fora viceinspetor da Fábrica da Pólvora.

Eis a letra do decreto que instituiu o Real Jardim Botânico:

"Tendo mandado estabelecer na Fazenda da Lagoa, de Rodrigo de Freitas, um jardim para plantas exóticas: sou servido que ele se aumente, destinando-se lugar próprio, o mais próximo que for possível para uma plantação de cravo e algumas outras árvores de especiaria; sendo diretores João Severiano Maciel da Costa e João Gomes da Silveira Mendonça, a cujo cargo está a do jardim que ali se acha estabelecido.

E ficará este novo estabelecimento anexo ao Museu Real para se fazerem pela folha dessa repartição as despesas necessárias, assim como a arrecadação do que em qualquer tempo possa produzir; do que se apresentará, nos tempos competentes, o devido balanço ao meu Real Erário, pelos diretores deste estabelecimento, que hei por bem fique na inspeção do ministro e secretário de estado do Reino por quem me serão presentes os negócios relativos a este estabelecimento.

Thomaz Antônio Villanova Portugal, do meu Conselho ministro e secretário de Estado dos Negócios do Reino, encarregado da Presidência do Real Erário, o tenha assim entendido e faça executar. 1819."

Palácio do Rio de Janeiro, em 11 de maio de

Em 1 de maio de 1811, o agrônomo Paul Germain desembarcara em Pernambuco, a chamado de D. João. Consigo trouxera, na Galera Princeza D. Maria Tereza várias plantas da Ásia cultivadas nos jardins de Caiena, e que o mesmo conselheiro Maciel da Costa, então intendente-geral, enviara ao Jardim de Aclimação de Olinda.

$O$ rei, para dar mais extensão à multiplicação de plantas, mandou estabelecer jardins filiais em Pernambuco, Bahia, Minas Gerais e São Paulo. A direção deste último foi entregue ao dr. João Batista Badaró, natural de Genebra, que havia feito estudos botânicos e excursões nas planícies da Lombardia, no Monte Cenis e na Sardenha.

Quando a 1 de novembro de 1817 deixou o governo de Caiena, embarcando na escuna portuguesa Andorinha, Maciel da Costa trouxe ainda outros vegetais úteis; entre eles a cana-de-açúcar, conhecida sob a denominação de cana-de-caiena.

Todas essas plantas estavam em pleno desen- volvimento na época da promulgação do decreto acima.

Compreendendo o valor dessa empresa, o conselheiro Arriaga apressou-se em enviar ao novo Real Jardim Botânico sementes e estacas de caneleira ${ }^{4}$.

Essas diversas plantas foram cuidadosamente cultivadas no Real Jardim Botânico, aí se desenvolveram de modo tão satisfatório que, em pouco tempo, eram espalhadas, por multiplicação, pelos jardins botânicos filiais da Bahia, Minas Gerais, Pernambuco; daí por todo o país.

Infelizmente essa época de florescimento não foi de longa duração, porquanto no jardim que serviu de berço a tais culturas, apenas se encontra um ou outro exemplar desses vegetais, que salvaram-se, ou da incúria ou do vandalismo, e que são atestados eloquentes desse tempo próspero.

A importância da cultura do cravo-da-índia deixou apenas hoje como recordação, algumas velhas árvores que se encontram bordando uma das aléas do "Jardim Velho" no antigo Bosque das Caneleiras. Justamente tais plantas haviam recebido a maior soma de cuidados do príncipe regente. Em ocasiões de festas religiosas, principalmente as da Santa Casa de Misericórdia, no tempo de José Clemente Pereira, eram essas plantas destruídas, pois que encontrava-se a igreja inteiramente atapetada de foIhas de canela e de cravo-da-índia, arrancadas, sem escrúpulo pela conservação das árvores.

O terreno destinado à cultura do chá é ainda hoje conhecido, pois ladeia a Aléa Frei Custódio plantada de Terminalias (chapéus-de-sol). Nesse vasto triângulo, não se encontrava, em 1890, nenhum vestígio da antiga plantação; menos felizes ainda que o cravo-da-índia, os pés de chá haviam totalmente desaparecido.

Os exemplares que hoje se encontram às vistas do visitante foram plantados, como recordação do passado, pela administração atual, que os foi buscar nos arredores, para onde os pássaros tinham tido o trabalho de conduzir as sementes, que ali germinaram.

A medida que o Real Jardim se enriquecia, D. João VI cada vez mais se interessava em seu desenvolvimento. Assim é que ele aí passava dias inteiros, animando os trabalhos com sua presença. Entretanto, dois anos depois, era obrigado a deixar o Brasil, a chamado das Cortes de Portugal, para onde embarcou a 25 de abril de 1821, deixando como príncipe regente seu filho $D$. Pedro.

Desejando continuar a obra de seu pai, e conhecendo a importância de tal empreendimento, D. 
Pedro tomou o Jardim Botânico sob sua proteção. Por decreto de 29 de fevereiro de 1822, separou-o do Museu Nacional, colocando-o sob a alçada do Ministério do Interior, mais tarde Ministério do Império.

Entretanto, raiou a aurora do 7 de Setembro de 1822. Nessa época, com as lutas e as dissensões políticas, o Jardim foi inteiramente descurado.

Entretanto, quando, depois da dissolução da Constituinte, em 25 de março de 1824, foi dada ao Império uma constituição duradoura, vemos entre os nomes dos que a assinaram os dos dois diretores do Jardim, eleitos deputados em 3 de junho de 1823. Maciel da Costa, um deles, chegou mesmo a ser o ministro do Império que referendou tal ato.

Sobre esse assunto pedimos licença para abrir parênteses, a fim de assinalarmos uma série de coincidências notáveis entre esses dois estadistas.

João Severiano Maciel da Costa e João Gomes da Silveira Mendonça eram naturais de Minas Gerais; ambos se chamavam João; ambos foram nomeados diretores do Real Jardim Botânico em 11 de maio de 1819; ambos eleitos deputados à Constituinte em 3 de julho de 1823; ambos escolhidos senadores em 22 de janeiro de $1826^{5}$; ambos nomeados conselheiros de Estado em 13 de novembro de 1823; ambos tiveram pastas no terceiro gabinete do Primeiro Reinado; ambos, afinal, morreram marqueses, um de Queluz e outro de Sabará.

Tendo sido nomeados conselheiros de Estado, nomeação confirmada pela Constituição de 25 de março, tiveram eles de ceder a administração do Jardim a frei Leandro do Sacramento, primeiro diretor botânico do estabelecimento, no Primeiro Reinado.

O Jardim de Aclimação se transformou, por esse fato, em Jardim Botânico, abandonado, portanto, o terreno da simples introdução da cultura empírica para passar a trabalhos mais sérios de experimentação e de estudo. Tornava-se necessária uma organização verdadeiramente científica e, nessas condições, ninguém melhor que frei Leandro do Sacramento ${ }^{6}$ para dar tais bases. Impelido por vocação irresistível, deixando o silêncio do claustro para ser o primeiro professor da cadeira de botânica da Academia de Medicina e Cirurgia, cadeira que foi tão nobremente ilustrada, o ilustre carmelitano, apesar de sua saúde enfraquecida e de seus cinqüenta janeiros, aceitou a espinhosa tarefa e entrou em exercício do cargo em fins de março de 1824.

De tal modo se houve nessa delicada comissão que, ainda hoje, tudo o que o Jardim pode oferecer de notável em trabalhos antigos é devido a seu espírito ativo e à sua inteligência, unicamente empregada sob o ponto de vista científico.
Entrando em exercício, encontrou ele o Jardim em deplorável abandono.

A plantação do chá estava inteiramente descurada. Ocupou-se o novo diretor especialmente do assunto, chegando mesmo a escrever uma brochura sobre a plantação, cultura e preparo de tão útil ternstroemiacea. Foi tão feliz que, por seus esforços em pouco tempo, só se bebia, no Rio de Janeiro, chá preparado no Jardim Botânico.

Aumentou ele consideravelmente a área cultivada; aterrou vários pontos baixos; delineou uma cascata; cavou o lago que até hoje faz o encanto dos visitantes; traçou diversas aléas que mandou plantar de mangueiras, nogueiras, longanas, pitombas, pão-de-jangada e cravo-da-índia; construiu um cômoro de terra artificial, no qual edificou a Casa dos Cedros ou Castelo, tendo ao centro mesa de granito, conhecida até hoje por Mesa do Imperador, em conseqüência da predileção que D. Pedro I e ll mostravam por colações naquele lugar. Aíainda estabeleceu frei Leandro um quadrante solar, reconstruído pela atual administração.

Em 1825, distribuiu plantas e sementes pelos jardins do Pará, Pernambuco e Bahia e, em 1829, enviou ao Jardim Botânico de Cambridge diversas espécies vegetais em troca de outras que dali haviam sido mandadas pelo vapor americano Warren. Mandou, mais tarde, para o Rio Grande do Sul, sementes de nogueiras Bois Noir e Bencrult.

Também, quando, em 1 de julho de 1829, a morte veio roubá-lo a seus trabalhos, o Jardim se achava transformado.

A ele se devem as cercas de murtas, de crótons e de hibiscus (mimos-de-vênus), cortados cuidadosamente e que ainda hoje fazem o encanto dos visitantes, pela regularidade, no corte e vivacidade de cores, embora os jardins modernos tenham abandonado tal sistema.

Foi frei Leandro que começou a grande bacia do repuxo da parte central da grande aléa das palmeiras; a morte não o deixou terminar tal trabalho que seu sucessor levou avante.

A tradição nos apresenta o ativo e sábio carmelitano sentado à sombra de uma velha jaqueira, contemporânea de outras que ainda hoje existem, animando os escravos que cavavam o lago e transportavam terra para o cômoro de que já falamos, com esta frase característica: "como formigas... minha gente... como formigas..."

Bernardo José de Serpa Brandão ocupou interinamente a administração durante a moléstia de frei Leandro; morrendo este, foi nomeado diretor efetivo do Jardim. 
Durante 22 anos, pois tantos foram os da sua administração, limitou-se a conservar o que lhe legara seu antecessor; apenas terminou os trabalhos do lago, começados por esse último.

Foi durante sua administração que, em 14 de maio de 1830, o célebre historiador monsenhor José de Souza Pizarro de Araújo, autor das Memórias do Rio de Janeiro, foi repentinamente fulminado por uma apoplexia, quando passeava por uma das aléas do Jardim.

Foi ainda, no tempo de Serpa Brandão, que floresceu pela primeira vez, a Oreodoxa oleracea Mart. trazida da llha de França em 1809 pelo chefe de divisão Abreu e plantada no local em que até hoje se a encontra pela própria mão de D. João VI. Por esse fato deu-se ao vegetal o nome de palmeira-real, que mudou-se para palmeira-imperial, para o que não existe razão de ser.

Até então, os diversos edifícios, oficinas e alojamentos da antiga Fábrica de Pólvora tinham ficado independentes da direção do Jardim Botânico. O artigo $4^{\circ}$. do decreto de 24 de outubro de 1832 dava jurisdição sobre tais dependências, enquanto que o artigo 41 do mesmo decreto autorizava o governo a providenciar para nelas executar melhoramentos que as adaptassem aos fins da nova instituição. Enfim, os artigos 4 e 5 da lei de 12 de outubro de 1833 anulavam os arrendamentos de terrenos contíguos e ordenava sua limitação definitiva sob a vigilância do diretor do Jardim.

O pessoal foi então organizado. Compunha-se de um diretor, dois jardineiros, um feitor dos escravos, um agente e sessenta escravos dos dois sexos. Esses escravos ganhavam 160 réis por dia los adultos) e 120 réis as crianças. Habitavam o espaço de terreno que ainda hoje se encontra com construções, em frente ao portão que conduz à residência do diretor do Jardim e tinham roças particulares no terreno que medeia hoje, entre a estufa e o aquário. Aquele terreno não pertence mais aó estado.

Como o Jardim tornara-se, no Segundo Reinado, o ponto predileto de passeios, cada vez mais freqüentado, o regente Pedro de Araújo Lima, depois marquês de Olinda, em nome do imperador, deu-lhe por decreto de 6 de setembro de 1838, um regulamento policial que facilitasse aos simples curiosos a vista do jardim e aos que aí apareciam para fins mais sérios, como o estudo e investigação dos vegetais aí existentes.

Esse regulamento, que por muito tempo foi executado em todos os seus artigos, foi, nos últimos tempos, inteiramente abandonado, de modo a chegar-se mesmo a ignorar suas disposições principais.
Os absusos, porém, tomaram tal caráter nos últimos tempos, que a administração atual teve necessidade de ir procurar nos arquivos aquele decreto que nenhum outro revogava e pô-lo em execução, de acordo com a legislação atual, na parte relativa à punição de delitos, isso autorizado por Aviso n. II, de 9 de julho de 1890.

Em 1851, Bernardo Brandão, já bastante velho e enfraquecido, conseguia ser aposentado e substituído pelo senador do Império Cândido Baptista de Oliveira.

Grandes e importantes transformações vieram em pouco tempo provar o acerto da escolha e a atividade inteligente do administrador.

O velho portão de madeira foi substituído por um outro de formas mais elegantes, mas que em 1893, foi também substituído por entrada mais ampla, mais alta, que a gravura neste volume perfeitamente apresenta. Foram construídas diversas pontes e valetas para escoamento de águas de chuva; a canalização de água foi reparada e completada mesmo em 1853, por um aqueduto que ainda hoje existe. Esse trabalho sólido e bem construído sobre grandes arcadas, passa superiormente sobre o Vale da Margarida, onde havia uma grande cultura de bombonaça (Carludovica palmata Rz. et Pav.) o deu lugar a que se fundasse uma fábrica de chapéus, bem conhecida por Fábrica de Chapéus de Chile. Infelizmente essa indústria, como a do chá, foi aos poucos definhando, até desaparecer.

A fábrica fora estabelecida sobre os destroços de um edifício onde existia a antiga abegoaria, edifício que conserva até hoje o nome de Chile, e que serve de morada a trabalhadores e depósito de ferramentas e utensílios.

Essa ativa direção durou apenas oito anos; Cândido Baptista retirou-se em 1859 e seis anos depois, a 26 de maio de 1865 morreu a bordo do paquete francês Le Peluge(?), que o transportava para a Europa.

O naturalista dr. Custódio Alves Serrão ${ }^{7}$ mais conhecido por frei Custódio (fora ele frade Carmelitanol, depois de ter exercido, durante longos anos, o cargo de diretor do Museu Nacional, vivia da aposentadoria de professor de química na Escola Militar, quando foi chamado em maio de 1859 para diretor do Jardim Botânico.

Químico distinto, além de amador apaixonado da botânica, ligava ele a seu grande saber, um espírito ativo e empreendedor. Era talvez o único que podia continuar o movimento de progresso dado por seu predecessor e impedir a decadência de um estabelecimento que a falta de homens competentes poderia conduzir ao descalabro. 
Coincidência notável! Um religioso carmelitano, primeiro diretor no Primeiro Reinado, tinha sido chamado para organizar o Jardim e elevá-lo à altura de um verdadeiro estabelecimento científico; um outro religioso, da mesma ordem, primeiro diretor científico, no Segundo Reinado, foi chamado para erguer da espécie de começo da decadência do mesmo estabelecimento desde a administração de Serpa Brandão. E esse religioso, com um outro franciscano, frei Velloso, formaram a tríade dos grandes botânicos do Brasil!...

Infelizmente, frei Custódio não pôde ser apreciado por seu justo valor. Animado das mais louváveis intenções, havia ele traçado um vasto plano de reformas ${ }^{8}$. Em dois anos classificou os vegetais cultivados na grande área, trabalho abandonado e mesmo perdido desde a morte de frei Leandro. Começou a plantação de árvores que fornecem madeiras de lei. Mas, cheio de desgostos pela ingratidão dos contemporâneos e do governo ${ }^{9}$, deu sua demissão em 1861, retirando-se para uma pequena casa, onde viveu só, até 10 de março de 1873. Aí, em plena floresta, à sombra da Pedra Bonita, sobre as fraldas do maciço da Gávea, só tendo por companheiro um rapaz (preto), que lhe era indispensável, principalmente quando a vista faltou-lhe, viveu doze anos, desprezando e fugindo o mundo e os homens, que Ihe haviam sido tão pouco generosos, entregue unicamente à ciência que servia-lhe de consolação nos últimos anos de vida.

$O$ diretor atual do Jardim, que teve a felicidade de ser uma das testemunhas daquele pobre cego, lembra-se, com saudades, das horas passadas perto do venerável ancião em comunhão de entusiasmo, que apagava a diferença de anos, enquando que os lábios do velho deixaram escapar verdadeiras jóias científicas.

A demissão de frei Custódio marca o começo de uma segunda fase do Jardim, durante a qual, foi o estabelecimento desviado do fim de sua criação. Vejamos, em detalhe, os acontecimentos que deram tal modificação.

Em 19 de novembro de 1860, o secretário do Instituto Fluminense de Agricultura, o falecido dr. Frederico Leopoldo Cesar Burlamaqui, apresentou à sociedade moção tendente a reclamar do governo a administração do Jardim. Aprovada tal moção foi feita a competente requisição, à qual o governo aquiesceu.

Frei Custódio, homem de ciência, revoltou-se contra o fato, mostrando as desvantagens que nasciam de fazer depender um estabelecimento como o Jardim Botânico dos caprichos dos diretores de uma associação particular. Reclamou, mas, não sendo atendido, retirou-se, como vimos.
A transmissão fez-se sem obstáculos. O estado retirou os escravos que foram substituídos por trabalhadores livres e o Instituto tomou conta do Jardim.

O próprio dr. Burlamaqui, a quem o Instituto devia a aquisição, foi nomeado diretor-fiscal do Jar$\operatorname{dim}$. A direção das culturas foi confiada a Harmann Herbster. Este, retirando-se, em agosto de 1862, foi substituído por Joaquim de Souza Lisboa, antigo feitor do tempo de Serpa Brandão. Lisboa retirou-se do Jardim em dezembro de 1884 e faleceu em 18 de julho de 1894, com 86 anos de idade.

Tiveram, na época, começo vários trabalhos. Aterraram-se diversos pontos e o engenheiro Hugue de Clare levantou a planta do jardim. Infelizmente, esse trabalho parece-me estar perdido, pois ninguém me dá notícia de seu paradeiro.

Entretanto, todos esses trabalhos apenas redundaram em despesas que não eram compensadas; tanto que em sessão do Instituto, de 12 de maio, foi proposta a rescisão do contrato com o governo.

Em 6 de março de 1863, o conselheiro Barão de Capanema renovava a mesma proposta. Afinal de contas, foi decidido por maioria que se conservaria o Jardim até que as circunstâncias aconselhassem o contrário.

Por esse tempo, foi contratado na Europa, em 3 de setembro de 1863, o dr. Karl Glasl, professor de agronomia em Viennia d'Austria, para dirigir uma escola de agricultura e uma fazenda normal que o Instituto pretendia fundar. Para essa fazenda foram mesmo cedidos pelo visconde de Mauá terras de sua propriedade em Sapopemba.

Entretanto, tendo o dr. Glasl declarado, depois de exame, que os terrenos próximos ao Jardim eram superiores àqueles, o Instituto obteve a desapropriação da Fazenda do Macaco para sede do novo estabelecimento. $O$ diretor dessa dependência assumiu também a direção do Jardim Botânico, embora subordinado ao diretor-fiscal, então o dr. Sebastião José Ferreira Soares. O dr. Glasl tomou posse do cargo a 18 de outubro de 1863.

Por esse tempo foi chamado o químico $\mathrm{A}$. Krauss que montou um pequeno laboratório, em terras do Jardim, mas longe da área cultivada.

Os trabalhos começaram em 1864. Fez o dr. Glasl aumentar a antiga oficina dos pilões, para aí montar motores hidráulicos. As máquinas foram na verdade montadas, mas nunca funcionaram.

Parece, por uma ata do Instituto, que nesse mesmo ano de 1864, modificaram-se certos artigos do regulamento, suprimindo-se o cargo de diretorfiscal e criando-se o de diretor-científico, que coube 
ao mesmo dr. Glasl. São, porém, fatos a verificar, nada tendo eu podido obter de certo, pois que não conheço os respectivos atos oficiais, e sim referências, como disse.

Seja o que for, em 1867, reorganizou-se a fábrica de chapéus de Chile, sendo contramestre o peruano José Assuncion Rengifo. Retificou-se uma parte do Rio Macacos, organizando-se os viveiros somente em 1868.

Quanto ao Jardim, desde que seu diretor estava distraído pelo estabelecimento da fazenda normal, ali não se encontrava interesse algum científico; transformou-se em simples jardim de recreio. Foi aberto francamente ao público e houve mesmo a condescendência de colocarem-se ali muitas mesas de madeira como nas estalagens de aldeia: quatro pés toscos suportando algumas tábuas pintadas de verde. Foram então facilitados os pic-nics ao ar livre e tornou-se um simples jardim de recreio. Assim, era impossível considerar-se o Jardim um estabelecimento científico sério, a contrastar com o título que conservou de: Jardim Botânico.

Grandes panos de grama, cheios de vegetais exóticos isolados ou em grupos, quase todos comprados a horticultores, plantados sem ordem, sem classificação, sem uma indicação apenas.

Com a força de vegetação no clima do Rio de Janeiro o passeio tornou-se em pouco tempo um grande parque encantador, excitando a admiração dos visitantes.

Infelizmente, como triste reverso da medalha, certas alamedas sombreadas, certos grupos lembravam, ao menos pela elegância e beleza grega, os bosques sagrados de Paphos e Amathonte, enquanto, nas moitas próximas do lago, ruidosos cânticos de culto do Baccho moderno recordavam os furores harmoniosos das mênades.

E o visitante estudioso, não encontrando elementos que guiassem seus passos no terreno da ciência, saía desses lugares encantadores, invocando os manes gloriosos de frei Leandro e frei Custódio.

O laboratório de química, algum tempo abandonado, foi restaurado pelo dr. Daniel Henninger, em 1874. Em 28 de julho de 1880, o dr. Henninger foi substituído pelo dr. Otto Linger, químico, que conservou a direção até fim de 1889 .

Os trabalhos ali feitos em quinze anos constaram de análises de canas, terras e algumas plantas. Foram publicados na Revista Agrícola, do Instituto. Talé o único trabalho científico que devemos a esse longo período, que vai de 3 de setembro de 1861 aos primeiros meses de 1890. Além dessas análises, inu- tilmente qualquer nota para o catálogo das plantas cultivadas.

Enfim, em 19 de maio de 1883, depois de grandes trabalhos para desenvolvimento da fazenda normal, faleceu o dr. Glasl, deixando no Jardim um atestado de seus trabalhos, isto é, a gruta artificial, que teve, por séria reparação, de ser por mim, salva da destruição, e os grandes grupos de plantas. Foi o segundo diretor que morreu no estabelecimento.

O conselheiro dr. Nicoláo Joaquim Moreira que o sucedeu, ocupou-se um pouco do Jardim Botânico. Teve, segundo sou informado, idéia de organizar um catálogo de plantas cultivadas. Mas penso não ter conseguido coisa alguma, porque nunca apareceu semelhante trabalho. Em 1884, 1885 e 1886, os relatórios do Jardim Botânico mencionam reclamações constantes do mesmo diretor.

Apesar dos obstáculos e da má vontade da administração superior, conservou o parque, reformou o portão principal, replantou a Aléa Frei Custódio com a Terminalia cattapa Linn. prolongou a das palmeiras, aumentou o salão dos bambus, reconstruiu as paredes do grande repuxo e plantou diversos grupos novos e fez a Rua das Arecas. Mas, desanimado pela oposição constante que sofria e pelas lutas suscitadas pelo Instituto, deu sua demissão em 6 de dezembro de 1887.

Nesse mesmo dia, na qualidade de presidente do Instituto Fluminense de Agricultura, assumiu interinamente a direção do Jardim Botânico o dr. Pedro Dias Gordilho Paes Leme, que declarou, em seu relatório de 31 de março de 1888, ter tomado a "árdua tarefa de reorganizar serviços que reconhecera imperfeitos".

Durante sua administração de mais de dois anos, entretanto, nada foi feito de modo a ser executada aquela declaração; achamos unicamente, como vestígio de sua passagem pelo Jardim, a transformação dos viveiros e a abertura de algumas vielas através de um dos panos de gramas. Esse último trabalho foi das mais funestas conseqüências; abateram-se, para abrir uma rua, os únicos exemplares que havia no Jardim: a carnaúba (Copernicea cerifera Mart.) e a bacaba (Enocarpus bacaba Mart.).

Em 24 de dezembro de 1889, demitiu o dr. Linger de chefe do laboratório de química e viu ser suprimido o asilo agrícola e desligado o Jardim Botânico do Instituto Fluminense por portaria do Ministério da Agricultura, de 25 de março de 1890. Assim terminou sua administração.

O diretor atual se achava à testa da administração do Museu Botânico do Amazonas, que organizara, quando, em 6 de fevereiro de 1890, recebeu convite do governo provisório da República para di- 
rigir o Jardim Botânico do Rio de Janeiro. Aceitando o convite, foi nomeado diretor deste, por portaria de 25 de março, e entrou em exercício a 1 de junho.

Nesse intervalo de tempo, ocupou inteiramente o cargo de diretor o bacharel Joaquim Campos Porto, nomeado por aviso de 31 de março, o qual tomou posse da administração a 2 de abril.

Entregue a seu fim primitivo de Jardim Botânico sob a alta administração do Estado, o estabelecimento ressentia-se de reformas radicais.

O primeiro cuidado do diretor foi apresentar ao ministro da Agricultura, general Francisco Glycerio, um projeto de regulamento de polícia interna, que não é mais que uma modificação, imposta pela diferença de legislação do regulamento de 6 de setembro de 1838, já citado. Sua excelência aceitou o alvitre, aprovando o projeto.

Já, em 12 de junho, apresentara ao mesmo ministro um projeto de organização, o qual deu em resultado o Decreto n. 518, de 23 do mesmo mês, que aprovava a nova organização.

Pôde então o diretor ocupar-se seriamente das reformas morais e científicas reclamadas pelas circunstâncias.

O regulamento de polícia interna executado estritamente embora com a maior dificuldade no começo, moralizou o Jardim, suprimindo entrevistas e pic-nics, obtendo perfeita conservação dos vegetais. Por outro lado foi levantada a planta do jardim, único trabalho hoje conhecido, pois que o de Hugue de Clare não me caiu ainda sobre as vistas. Valetas e canais e bueiros foram abertos para dar escoamentos às águas de chuva, que em diversos pontos, formavam verdadeiros pântanos; várias aléas foram aterradas; grupos limpos e replantados de modo a serem utilizados para estudo. Os viveiros foram reorganizados e as plantas classificadas especificamente; estabeleceu-se um grande viveiro cercado de estufas; as ruínas do depósito de artigos da antiga Fábrica de Pólvora foram reerguidas, ficando os viveiros inteiramente cercados; em frente ao belo portão, interessante recordação histórica da época colonial, foi aberta uma grande avenida plantada de árvores de madeiras de lei. A esse portão chega-se atravessando a nova ponte sobre o Rio Macacos, cujo curso foi mudado, pois as águas, em certas épocas inundavam o Jardim. As canalizações d'água foram restauradas e aumentadas; um antigo reservatório reconstruído, a fim de fazer crescer um volume do líquido para os lagos, cascatas e repuxos; fontes Wallace foram colocadas de distância em distância para refrigério dos visitantes; lugares reservados (water closets) construídos.
Novos terrenos foram abertos, aterrados e ajardinados, e o número de espécies extraordinariamente aumentado. Todas as alamedas passaram então a ter denominações, que recordam os nomes dos passados diretores. As mesas que desonravam o Jardim foram arrancadas aumentando-se o número de bancos.

Em compensação organizou-se o museu onde está começado o herbário nacional; foram reconstruídos prédios do Jardim; construída uma estufa, aquário, plantado um arboreto, além de outros melhoramentos de que dão conta os relatórios enviados ao Ministério da Agricultura, hoje da Indústria.

Não podendo, senão por sistema de verdadeiro vandalismo, mudar o plano do Jardim, o diretor esforçou-se o mais que pôde para apropriá-lo a seus destinos. Todas as plantas foram classificadas e devidamente etiquetadas.

A flora brasileira retomou seus direitos, senão exclusivos, ao menos preponderantes, espalhandose plantas nacionais pela nova área acrescida ao Jardim pela derrubada de pontos de mata e capoeirões. Hoje esses pontos oferecem belíssimo aspecto.

Enfim, o presente catálogo foi delineado com o fim de tornar conhecido um estabelecimento científico em seu início, embora date de longos anos sua fundação; de explicar que circunstâncias entravaram seu desenvolvimento; de facilitar, enfim, ao investigador, ou mesmo ao simples curioso, o estudo das plantas que aí se cultivam. Foi essa a nossa ambição.

Depois do resumo sucinto da vida e dos trabalhos daqueles que até hoje têm dirigido o Jardim Botânico, justo é que em poucas palavras, contemos a história de algumas plantas que aí se encontram.

O mais antigo vegetal, o único representante da floresta virgem que cobriu outrora aqueles lugares é uma Guarea trichilioides Linn. centenária, o itó dos indígenas, hoje conhecido por carrepeta de marinheiro. Essa planta encontra-se logo à esquerda do portão principal. É o decano dos vegetais indígenas do Jardim.

Do lado direito vê-se um soberbo exemplar do li-tchi, da China, o Nephelium litchi de Baillon ou Litchi chinenses de Sonnini, cujo nome vulgar o vulgo mudou em lichia. É um dos raros sobreviventes da remessa que fez Luiz de Abreu de plantas cultivadas em Caiena, em 1809. Originária da China, o li-tchi cresce abundantemente nas províncias de Fokien, de Cantão e de Quansi. Os frutos secos, como ameixas, pelos chins, são misturados ao chá, a que comunicam, dizem, sabor ácido agradabilíssimo. Conservados no mel ou álcool de arroz, os mesmos frutos são mandados para Pequim, a fim de serem servidos ao imperador. 
Mais feliz que o li-tchi, o Nephelium longana Lam, long yen ou olho-de-dragão dos chins, olho-deboi dos brasileiros, se acha representado por numerosa descendência. Importado em 1809 por Luiz de Abreu, propagou-se tão bem que, em 1825, frei Leandro plantou uma aléa que ainda hoje existe. Esta aléa, denominada hoje de Frei Leandro, atravessa a praça onde se acha o grande repuxo da aléa das palmeiras e dirige-se à direita para a rua das mangueiras e à esquerda para a cascata. Embora velhos, sem gaIhos, vivem os exemplares, como recordação do passado. Originário também da China, o Nephelium longana produz frutos muito apreciados pelos naturais.

Contemporâneos dessas duas sapindáceas, 0 primitivo jardim da Fábrica de Pólvora encerra várias lauráceas como o Laurus Cinammomum Linn., o L. persea ou Persea gratissima Gaertn e o L. camphora Linn. O primeiro fora propagado de modo a formar um verdadeiro bosque, o legendário Bosque das Caneleiras. Hoje desapareceu inteiramente.

Resta ainda a noroeste do Jardim, uma bela rua de canforeiras. Quanto ao Laurus persea ou abacate, se quase desapareceu do Jardim não é menos certo que deu sementes para que a planta se propagasse abundantemente por todo o Brasil.

Da importação de 1809, restam ainda alguns raros exemplares de cravo-da-índia (Caryophillus aromaticus Linn.); fruta-pão (Artocarpus incisa Linn.); jaqueira (Artocarpus integrifolia); a noz-moscada (Myristica fragrans Hout. ou officinalis); o cajamanga (Spondias dulcis Torst.); a nogueira (Aleurites molucana Willd.); o sagu (Cycas revoluta Thunb.); e finalmente a flor-de-coral-da-índia (Renanthera coccinea Lour.) que tem tomado posse de velhos troncos de árvores do jardim. Daí saíram todos os vegetais acima para espalharem-se por todo o país.

0 curioso e o amador podem ainda ver a veIha jaqueira a cuja sombra assentava-se frei Leandro, jaqueira que forneceu sementes para as aléas que ele fez plantar. Dessa aléa ainda hoje se encontra, perto do lago, à esquerda da antiga Casa dos Cedros, hoje monumento a frei Leandro, velho exemplar, rodeado de bancos para repouso dos visitantes; vigorosa e fértil, apesar dos seus 82 anos, a velha jaqueira é ainda a que dá os melhores frutos.

Foi ainda frei Leandro que fez plantar os dois exemplares de Eucalyptus gigantea L'Hér. colocados na parte posterior do mesmo monumento.

A tradição reza que a casa suberosa que serve para cobrir casas dos selvagens australianos, servia no Jardim para os escravos que queriam se desembaraçar de um companheiro qualquer que os incomodasse. A análise química, entretanto, não me revelou princípio algum tóxico; somente mostrou ta- nino em grande quantidade, em vários pontos do tronco.

Mais tarde introduziram-se no Jardim: a frutade-conde (Anona squamosa Linn.); a carambola (Averrhoa carambola Linn.); o bilimbi (Averrhoa bilimbi Linn); a groselha (Ribes rubrum); a pimenta-doreino (Pipernigrum Linn.) e a quassia (Quassia amara Linn. fil.).

Essas diferentes plantas foram importadas por Paul Germain, de quem já falamos, quase todas da Ilha de França.

A plantação que teve maior desenvolvimento foi, como vimos, a do chá. Além das sementes de Thea viridis Linn., enviadas de Macau, vieram outras de Thea bohéa Ait., por intermédio da Inglaterra. Para aromatizar o chá, importou-se ao mesmo tempo a flor-do-imperador (Olea fragrans Thunb.), cujos veIhos representantes não cessam de cobrir-se de flores, anualmente.

Das amoreiras importadas em 1811, ainda se encontram alguns exemplares do Morus alba e $M$. nigra.

O rotin ou rotang (Calamus rotang) e o juncoda-índia (Calamus asperrimus) formam maciços espessos, enquanto que a kola (Sterculia acuminata Palis), da mesma época pouco mais ou menos, só se acha representada por quatro exemplares, três no antigo bosque e um junto ao repuxo central. Dão pouca sombra; florescem anualmente, mas não chegam a dar frutos.

O ébano é introdução mais recente, foi introduzido em 1862, na mesma época da árvore-doviajante (Ravenala madagascariensis Adans), cujos grupos belíssimos ornam vários pontos, principalmente as bordas do grande lago.

O Mimusops ballata Gaertn., que também fornece a guta-percha, é representado por um soberbo exemplar.

Quanto às plantas exóticas de pura ornamentação, cujo plantio no Jardim remonta a 1860, foram elas compradas a horticultores estrangeiros.

Mencionemos quatro aléas plantadas por frei Leandro e cuja vegetação primitiva desapareceu. A aléa central, hoje Aléa Serpa Brandão, plantada de casuarinas que, em 1842, foram substituídas pelas palmeiras que fazem a admiração geral, uma segunda aléa, das nogueiras que, em 1854, foram substituídas por amendoeiras (Terminalia catappa Linn.); a que liga a aléa das Palmeiras à das mangueiras cujos saboeiros de fruto comestível ou pitombeiros (Sapindus esculentus Camb.) foram substituídos por bambus; finalmente, a dos antigos paus-de-jangada (Apeiba tibourbou Aubl.) desapareceu para dar lu- 
gar a algumas palmeiras indígenas dos gêneros Attalea, Orbignia, Cocos, Elaeis e outras.

Em 1842, foram plantadas as macaúbas (Acrocomia intumescens Dr.), entre as quais distingue-se o grupo conhecido pelo nome de Cinco Irmãos).

Da época de Serpa Brandão datam os bambus, que cobrem uma grande aléa e que fazem uma abóbada quase impenetrável ao sol, aléa que comunica a rua de mangueiras com a estufa.

Como maravilha de vegetação podemos ainda citar duas plantas: uma gameleira (Ficus sp.) nascida espontaneamente sobre um tronco de mimosa, cujo tronco atinge 2 metros de diâmetro e cujo cimo se eleva a 15 metros coberto inteiramente de barbas-de-velho (Tillandsia usneoides Linn.); outra é um flamboyant (Pointiana regia Bojer), plantada em 1859 , por frei Custódio. É talvez esse o melhor exemplar que se encontra no país, pois que mostra imensas raízes sobre o terreno (sapopemas) entrelaçadas de modo singular e pitoresco.

Muito de indústria reservamos para final deste capítulo a notícia sobre as palmeiras da aléa central do jardim.

Já dissemos o modo por que o chefe de divisão Abreu trouxera da llha de França as plantas que primitivamente aqui foram introduzidas. No número destas achava-se, uma palmeira conhecida por areca que não era mais que a Oreodoxa oleracea Mart. a cujo gênero pertenceu.

Encantado pela beleza do vegetal, o regente D. João quis plantá-la com as próprias mãos, a fim de inaugurar mais solenemente a nova instituição. Daí veio o nome de palmeira-real, nome que poderia confundi-la com a Oreodoxa regia.

Nossa palmeira-real é a O. oleracea Mart., a Euterpe caribaea Sprengel ou Areca oleracea Linneo.

A planta real tornou-se desde logo objeto de cuidados por parte dos diretores do estabelecimento. $E$, quando, pela primeira vez, a longa espada, abrindo-se, deixou escapar o elegante penacho do espádice que devia perpetuar a espécie, o diretor Serpa Brandão, querendo reservar para o Jardim o monopólio da árvore sagrada, fez recolher cuidadosamente todos os frutos antes da maturidade, mandando que os queimassem sob suas vistas.

Anualmente, a palmeira, aclimada em região favorável dava grande número de frutos; mas a vigilância ativa do diretor os fazia desaparecer. Apesar dessa vigilância, porém, deu-se na época, uma nova edição da comédia da Precaução inútil, sempre nova e sempre verdadeira. $\mathrm{O}$ atrativo do fruto proibido perdeu Eva e dotou nossos jardins do mais belo ornamento. Os escravos não eram incorruptíveis; afrontando as iras e os castigos do feitor, levantavamse à noite, subiam ao tronco liso da palmeira e apoderavam-se de sementes que vendiam a 100 réis cada uma.

Propagada por este meio, a palmeira-real não tardou a espalhar-se por tal modo que em certos lugares do Brasil tornou-se mais conhecida que as palmeiras indígenas.

A planta mãe ainda hoje aí se encontra, sem rival no mundo em beleza, balançando a 35 metros acima do solo seu grande penacho de folhas que coroam um espique de regularidade perfeita e que mede 1,30 metro de diâmetro na base.

As duas aléas, plantadas de sementes do exemplar primitivo, não encontram rival no mundo. Alger pode vangloriar-se da aléa do Jardim das Plantas, Caiena da sua savana, superior àquela. Entretanto, em extensão, regularidade, altura e vigor de vegetação a aléa das palmeiras-reais provoca a admiração de nacionais e estrangeiros como única.

Extensa de 740 metros, a aléa central conta 134 palmeiras de altura média de 25 metros, com 1 metro de diâmetro.

A Aléa Candido Baptista, lateral, paralela à rua do Jardim Botânico, da qual está separada por cerca de murtas, mede 550 metros de extensão e encerra 142 palmeiras com altura média de 22 metros mais ou menos.

Todas as palmeiras tem os espiques cobertos de liquens sobressaindo a Usnea seretina Sch., a Cladonia sanguinea Mart., a Parmelia perforata Sch., a Erioderma wrightii Nyl., a Physcia leucomella Mich. e outros, crescendo entre eles a Sophronitis coccinea Rich., o Epidendrum umbellatum Sw. e a Tillandsia bicolor Brog.

Quando tomei posse do cargo, tratei de mandar proceder à estatística geral das pessoas que procuravam o Jardim e desse modo pude verificar, e isso tem sido publicado mensalmente que, do começo de abril de 1890 ao final de junho de 1894, o estabelecimento foi visitado por 144.878 pessoas.

Da distribuição de plantas e sementes, posso também oferecer a seguinte estatística: de abril de 1890 ao final de junho de 1894 o jardim forneceu 4.810 exemplares de plantas diversas e $37.890 \mathrm{mu}-$ das de canas, para a Capital Federal e estados da República.

No mesmo período forneceu 925.668 gramas de sementes: 655.038 para o interior e 270.630 para o exterior, sendo as remessas para o exterior feitas para os seguintes pontos: Rússia, França, Alemanha, Holarda, Estados Unidos da América do Norte, Java, Inglaterra, Itália, Austrália, Trindade, Ceilão, 
Bélgica, Suíça, Espanha, Egito, Cuba, Servia, Romênia, Peru, Venezuela, Suécia, Vitória (Oceania), Jamaica, Calcutá, China, Áustria, Portugal, Algeria e Ilha Samoa.

O Jardim Botânico do Rio de Janeiro deste modo, está em relações com todos ou quase todos os jardins botânicos do mundo.

O Jardim é franqueado diariamente ao público, das 6 horas da manhã às 6:30 da tarde, no verão, e das 6:30 da manhã às 6 horas da tarde, no inverno. Às quartas-feiras e sábados, porém, a entrada é somente concedida a estrangeiros em trânsito, que não possam dispor dos outros dias da semana para tal visita.

O jardim pede e aceita quaisquer mudas ou sementes de plantas, que podem ser remetidas dos estados gratuitamente conforme determinações do governo.

O Jardim, em 1890, não possuía biblioteca nem herbário nem museu. Hoje, esse mal está em parte remediado, já pelas excursões, já pela aquisição de herbários riquíssimos doados pelo eximperador, sr. D. Pedro de Alcântara. Éa ele que o Jardim Botânico deve o começo da biblioteca e do museu, pois os primeiros livros e as primeiras plantas conservadas foram por ele oferecidos.

Depois de banido do país, D. Pedro que fora meu mecenas nos primeiros estudos botânicos, presenteou-me com o rico herbário e algumas obras botânicas que possuía. Embora essa dádiva fosse para mim motivo de reconhecimento, julguei ser intérprete do pensamento do ofertante, transferindo o presente ao Jardim Botânico, que daquele soberano recebera sempre as maiores animações.

Essa coleção figura no estabelecimento sob o nome de D. Thereza Christina Maria, como sucede com outras coleções doadas por D. Pedro a diversos estabelecimentos públicos do país.

Infelizmente essa importante dádiva não pôde ser aproveitada inteiramente, como fora para desejar, pois no antigo Palácio de S. Cristovão várias caixas de plantas ficaram totalmente estragadas pela água que caía no compartimento em que estavam.

Esse herbário pertenceu ao sábio professor Feé, professor de botânica da Universidade de Strasburgo, o qual escreveu sobre fetos, principalmente do Brasil. Foi principiado por Bergerete, remonta a 1760. Continha 25.000 espécies de plantas, e hoje ocupa a coleção de 110 caixas de folha-de-flandres, dispostas em armários apropriados.

Vários outros herbários encontram-se ainda no Jardim: de plantas da área cultivada, de plantas de Minas Gerais e de plantas do Amazonas.
Como se viu, frei Leandro do Sacramento, que fora o primeiro professor de botânica da Escola de Medicina, foi também, no Primeiro Reinado, o primeiro diretor técnico que teve o Jardim, o que o reformou e fez melhoramentos dos quais ainda hoje muitos perduram.

Era justo que o Jardim prestasse-Ihe uma homenagem de reconhecimento, que atestasse aos vindouros o valor do sábio botânico, amigo de SaintHilaire, cujo nome está perpetuado em muitas plantas por vários botânicos estrangeiros, como tributo de apreço ao seu saber; por isso, com os minguados recursos que possuía, a forças de economia, procurei levantar-Ihe um monumento.

Simples, modesto, de estilo rústico, levantei um pavilhão-estufa, que cobre o pedestal, sobre o qual assenta o seu busto, rodeado de flores que mensalmente são renovadas.

O monumento é octógono e para ele se entra por duas portas depois de subir uma escada de três largos degraus que circunda todo o edifício.

Está assentado sobre o cômoro feito pelo próprio frei Leandro, no centro da antiga casa dos cedros. Morrendo os troncos, foram cerrados e aproveitados para a grade que cerca o edifício. Junto fica, restaurado, o quadrante solar por ele estabelecido perto da mesa de granito que o mesmo mandou fazer para as refeições imperiais, pelo que conserva ainda entre o povo o nome de mesa do imperador. Fronteia o monumento o lago feito pelo mesmo diretor, ficando em frente, pelo lado posterior, a alameda de longanas, o grande repuxo e a jaqueira sob a qual ele se assentava para a direção do trabalho, e onde começou a agonia que lhe tirou a luz terrena.

Ergue-se o monumento, pois, no meio das obras que recordam a sua atividade. Interiormente, como quase não é conhecido no Brasil esse sábio brasileiro, ornam as faces das paredes coroas de bronze no centro das quais, sobre um fundo que indica uma nação; lêem-se os nomes das plantas que perpetuam o seu, e os dos botânicos estrangeiros que pagaram esse tributo de veneração. Todos os ângulos são ornados com vasos de flores assim como o chão e a base do pedestal.

Neste, uma placa de mármore cinzento contém a seguinte inscrição, em letras de ouro:
MEMORIAE
FR. LEANDRI DE SACRAMENTO
CARMILITARUM ORDINIS
CONIMBRICENSI UNIVERSITATE
SCIENTIIS NATURALIBUS DOCTI
PRIMI HERBARIAE PROFESSORIS 
MEDICAE SCHOLAE

FLUMINIS JANUARII

HUJUSQUE HORTI

PRIMI TECHNICI DIRECTOR

HOC MONUMENTUM

SEXAGESIMO MORTIS ANNIVERSARIO

KALENDAS JULII MDCCCXCIII

JOANNES BARBOSA RODRIGUES PUBLICI

AERARII AUXILIO

ERIGENDUM

CURAVIT

A tradução é a seguinte: "À memória de frei Leandro do Sacramento, da Ordem dos Carmelitas, formado em ciências naturais pela Universidade de Coimbra, primeiro professor de botânica da Escola de Medicina do Rio de Janeiro, e primeiro diretortécnico deste jardim, levantou este monumento, com o auxílio do governo, no $6 .^{\circ}$ aniversário de sua morte, no dia 1 de Julho de 1893, João Barbosa Rodrigues então diretor".

Ainda sobre trabalhos antigos de frei Leandro, não deixarei de consignar a restauração do repuxo começado por aquele diretor. Construído há setenta anos, achava-se esse repuxo com a bacia de mármore inteiramente estragada pelo tempo e pelas águas.

Tendo o governo mandado demolir o grande chafariz que se erguia no largo da Lapa, o qual tinha o material inteiramente novo, pois que nunca se prestara ao fim para que ali fora levantado, consegui obter esse material que, com o trabalho de colocação, custara cerca de cinqüenta contos de réis.

Levanta-se hoje o chafariz na parte central da aléa das palmeiras, a 6,50 metros do solo, dentro de um tanque de paredes de mármore, o qual tem 15,72 metros de diâmetro e 90 centímetros de profundidade.

É de ferro, fundido em Londres, com diversas alegorias, duas bacias, elevando-se no centro da maior quatro figuras que representam a música, a poesia, a ciência e a arte. Além da água que cai abundantemente das bacias, jorra ainda esse líquido das diversas figuras, de modo que, em pleno funcionamento, essa construção é de aparência magestosa. Teve começo o trabalho de reconstrução em fevereiro do ano corrente.

Como vimos, o Jardim Botânico estava disposto em parque, onde as diversas plantas se encontravam confundidas, em grupos esparsos pelos tabuleiros de grama ou bordando as aléas, e representadas por centenas de exemplares, mas na desordem que a arte estabelece para imitar a natureza.
Plantas inteiramente diferentes achavam-se reunidas, algumas majestosas e gigantescas, outras formando moitas belíssimas, tudo porém em parque que o público conhecia e admirava.

Como organizar assim um jardim metódico e científico?

Tornava-se necessário tudo destruir para começar, mas além do vandalismo, o público amaldiçoaria a administração que tal fizesse, pois na maior parte não conhece ele as exigências da ciência.

Por isso tratei de tudo aproveitar, reunindo as plantas, ao menos por afinidades, e dividindo o jardim por seções que, compreendendo a da casa do diretor tem uma área de 544.611 metros quadrados, cortada por cinco ruas, treze alamedas, sete vielas, quatro passagens, uma azinhaga, com uma extensão de 6.500 metros lineares. Estas divisões fecham tabuleiros de grama, onde existem mais de cinqüenta mil exemplares de plantas.

Aumentando consideravelmente hoje o número de plantas, acham-se nas seções as espécies por grãos de crescimento, mas todas com o mesmo número.

O parque é, pois, hoje um jardim sistemático de que as páginas que seguem darão notícia exata.

O visitante que quiser estudar uma família ou uma espécie unicamente, procurará o nome científico ou vulgar nos índices respectivos, por ordem alfabética e a achará na relação sistemática com todas as informações possíveis.

Desse trabalho resultou o presente livro, ainda imperfeito e incompleto, que será depois correto e aumentado logo que novos elementos de estudos me cheguem às mãos. Adicionei algumas vistas dos principais grupos ou plantas, para que mais facilmente o leitor orientado conheça o jardim. Muitas serão as faltas que nele devem aparecer, mas no curto espaço de tempo em que foi feito, sem auxílio de uma boa biblioteca e de um herbário, difícil, senão impossível, seria fazer mais, e isso me sirva de desculpa. Devo notar que, além das espécies aqui mencionadas, existem ainda centenas de outras ultimamente adquiridas e não-classificadas especificamente, umas em sementeiras e outras esperando a florescência, as quais aparecerão em apêndice.

Querendo dar maior utilidade a este guia julguei acertado apresentar uma curta diagnose das famílias e dos gêneros e de algumas espécies, a fim de poder servir também como de compêndio ao estudante de botânica e aos amadores. Mais completo seria se tivesse um indículo bibliográfico em cada espécie, para maiores estudos, mas propositalmente cometi essa falta, por escassear-me o tempo; 
para a busca. Sendo uma relação detalhada das plantas cultivadas somente no jardim, contudo, oferece dezenas de exemplos de quase todas as famílias naturais que praticamente se ficam conhecendo, sabendo-se os seus principais caracteristicos.

Imperfeito como é, muito feliz me julgarei se ele puder servir para animar a mocidade a estudar uma ciência tão útil que nos dá não só doces passatempos como gozos inocentes, fazendo conhecer as riquezas com que o Criador dotou a nossa pátria querida.

Tendo chegado tarde às minhas mãos novas informações, julgo que de algum modo completo esta exposição, oferecendo alguns dados históricos que se relacionam com fatos tratados nas páginas anteriores.

Assim é que, em 1832, sendo ministro da Guerra Manoel da Fonseca Lima e Silva, foi transferida a Fábrica de Pólvora da Lagoa Rodrigo de Freitas para a Estrela, onde até hoje se acha.

De 1829 a 1830 exportaram-se, para venda, 33 arrobas de chá, tendo sido enviadas treze para os navios de guerra. Possuía o jardim nešsa época quarenta escravos, número que em 1853, foi elevado a 67 e em 1854 a oitenta. Em 1861, como vimos, foram daí retirados.

Nesse mesmo ano de 1832, já o trabalho de classificação de vegetais empreendido por frei Leandro do Sacramento estava perdido. Existia apenas um viveiro. Essa declaração é feita pelo então ministro do Império, Joaquim Vieira de Silva e Souza, em seu relatório, que contém, sobre a matéria, o seguinte tópico: "no jardim não estão as plantas classificadas."

A idéia da fundação da fazenda normal, tornada efetiva, somente depois de 1861, já em 1837 tinha sido aventada, tanto que a Sociedade Auxiliadora da Indústria pedia por cinqüenta anos o horto para aquele fim, no que foi embaraçada por particulares que se achavam de posse das terras do estado, pertencentes ao estabelecimento.

Em 1840, na época própria para o fabrico do chá era o jardim franqueado ao público para aprender os processos respectivos. Então, o jardim "tornava mais sensível o quadro melancólico, pela progressiva decadência de seu arvoredo", segundo declara em seu relatório, o ministro Francisco Ramiro d'Assis Coelho.

Em 1843, tiveram começo as obras do portão, concluídas em 1854, e começou o cultivo do bichoda-seda.

Em 1847, foi incumbido frei Custódio Serrão de confeccionar o regulamento do jardim. Tal traba-
Iho foi levado a efeito, mas como para sua execução demandava grandes despesas, nunca foi promulgado.

Em 1855, o ministro Luiz Pedreira do Couto Ferraz manifestou-se favorável ao amuramento do jardim pela estrada de D. Castorina e a melhoramentos no Rio Macacos, por causa das contínuas inundações.

O último desses trabalhos foi feito pela atual administração. Quanto ao primeiro faz até hoje parte do plano de melhoramentos, sem que se tenham podido obter meios para tal fim.

Finalmente, em 1857, deram-se os primeiros passos para formação do Bosque, de madeiras de lei.

Como complemento do histórico deste jardim, devo ainda dizer algumas palavras sobre a parte policial.

No reinado do sr. D. João VI, o Real Horto era inteiramente privado e particular; foi só no reinado de D. Pedrol que se o franqueou ao público, isso mesmo com permissão do diretor, sendo os visitantes acompanhados por praça do corpo de veteranos, que tinham uma guarda no edifício denominado Salitre.

Até à administração Glasl, a entrada para o jardim era pelo portão chamado da coroa, que é o que dá hoje entrada para a casa do diretor.

Porteriormente, estes velhos servidores foram rendidos por outra guarda de imperiais marinheiros e estes por municipais permanentes.

Durante a minoridade do sr. D. Pedro II, a Regência, em nome do mesmo augusto senhor, expediu o regulamento que vai adiante publicado, sendo então franqueado o jardim ao público, que era policiado pelas mesmas praças.

Distúrbios causados pelas mesmas, entre os escravos que então ali trabalhavam, fizeram com que o diretor dispensasse a mesma guarda policial.

Em 1850, aquartelou então no mesmo edifício, onde residia a guarda policial, o $1^{\circ}$ ' batalhão de artiIharia, que para ali veio a fim de fazer exercícios práticos nas circunvizinhanças do Jardim com alunos da Escola Militar, retirando-se dali, em 1857, para o Rio Grande do Sul.

A polícia foi posteriormente feita pelo Corpo Policial até à minha administração em que passou a ser feito por um corpo de guardas do mesmo Jardim, tirado dos trabalhadores.

Esta medida tem dado os melhores resultados.

Este guia, nas duas primeiras classes, encerra: famílias, 71; gêneros, 411; espécies, 837. 
As 837 espécies são geograficamente distribuídas do seguinte modo: Europa, 96; Ásia, 114; África, 55; América do Norte, 43; América do Sul, 43; Brasil, 396; Oceania, 64; Pátria desconhecida, 26.

\section{Jardim Botânico, 28 de fevereiro de 1895.}

\section{J. Barbosa Rodrigues. Diretor.}

\section{Notas}

1. Çapô, que significa raíz, peua, chato, ypau, lagoa.

2. As plantas primitivamente trazidas de Caiena por esse chefe de divisão foram as seguintes: quatro moscadeiras (Myristica fragrans Hout.), quatro abacateiros (Persea gratissima, Gaertn.), dois pés de Litchi (Nephelium litchi Linn.), três caneleiras (Laurus cinammomum L.), dez turangeiras (Citrus pomum Adami Risso). Além dessas plantas, trouxe sementes de: Acacia lebbech Willd. (coração-de-negro), Cycas revoluta Thumb. (sagu), Artocarpus incisa Lin. (fruta-pão), Spondias sp. (cajás), areca - é a Oreodoxa oleracea Mart. (palmeira-real), como veremos.

3. Escolhido senador a 26 de junho de 1826 , morreu a 2 de julho de 1827.

4. A caneleira foi introduzida no Brasil pelos jesuítas. Em 1798, segundo Bernardino Antônio Gomes, havia vários exemplaresna Bahia e Rio de Janeiro. Nessa época escreveu ele a Membria sobre a canela do Rio de Janeiro, publicada em 1809. Por um catálogo publicado em 1789, vê-se que entre as plantas cultivadas no Horto de São José, do Pará, encontravam-se a caneleira, a jaqueira, a mangueira, o tamarindeiro, a teca, a noz-moscada e o cravo-daíndia.
5. Depois dos acontecimentos de 26 de janeiro de 1821, houve uma conspiração republicana e Maciel da Costa foi preso como conspirador. O decreto de 16 de março do mesmo ano o pôs em liberdade.

6. Era membro da Academia de Ciências de Munique, de Londres e da Real Sociedade de Horticultura de Gand. Organizou um catálogo das plantas então cultivadas no Jardim, catálogo que passou a seu sucessor, mas que desapareceu sem ter sido publicado. Em 1842, tal trabalho foi visto pelo sábio botânico Freire Alemão. Escreveu vários trabalhos botânicos, publicados em revistas alemãs assim como uma monografia das euforbiáceas.

7. Em 1811, entrou para o convento do Carmo, em Alcântara; em 1818 , seguiu para Europa, onde matriculou-se no Convento Colegial de Coimbra; em 1825, voltou ao Brasil; em 1826, foi nomeado lente de geologia e botânica da Academia Militar; em 1840 . teve secularização perpétua; em 1847, jubilou-se, retirando-se para a Gávea, depois de ter resignado o lugar de diretor do Museu. Morreu ao meio-dia de 10 de março de 1873.

8. Fazendo frei Custódio sua autobiografia ao dr. Antônio Henrique Leal, em 30 de setembro de 1805, dizia: "O estabelecimento estava desmantelado. Nos meios de administração, no pessoal, no material, desacreditava o país; e, portanto, eram urgentes medidas para reorganizá-lo, e eu não aceitava o encargo para servir de testemunha passiva de tanta vergonha e por isso propu-las de conformidade com as vistas de sua larga instituição". (Pantheon Maranhense - vol. IV. p. 356).

9. Tendo sido condecorado com a comenda de Cristo, respondia ele aos que davam-lhe parabéns: "Há engano manifesto, e isso entende-se seguramente com algum parente meu de igual nome; porque é impossível que, não sendo nunca lembrado quando servi ao país, só agora fosse, depois que morri para o mundo e vim enterrar-me nesta sepultura." (Op. cit. p. 278) 


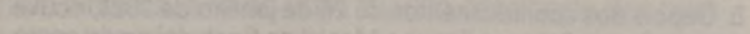

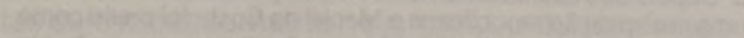

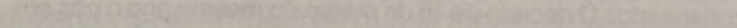

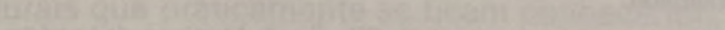

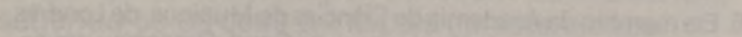

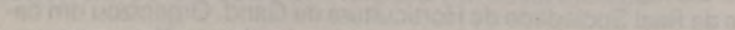

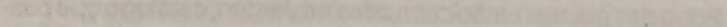

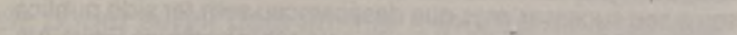

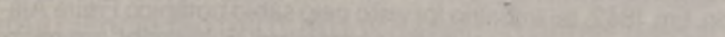

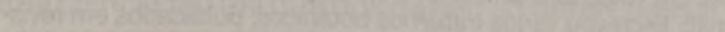

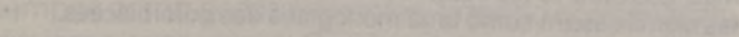

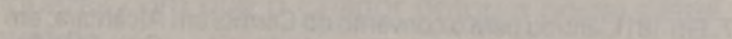

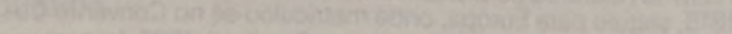

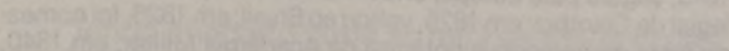

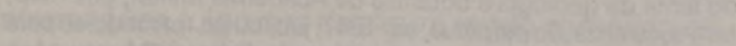

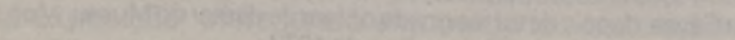

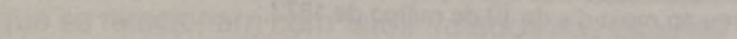

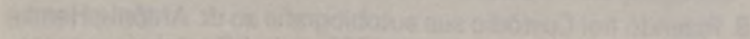

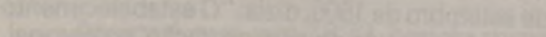

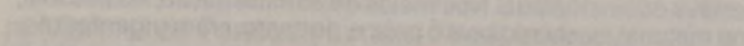

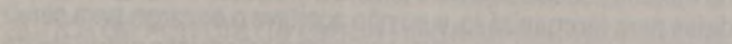

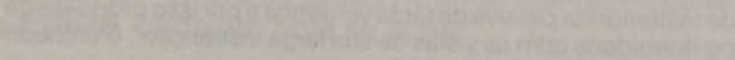

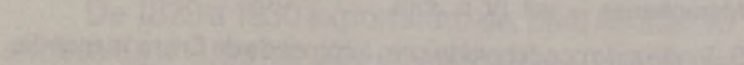

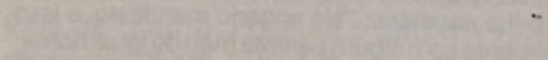

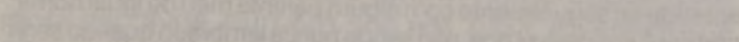

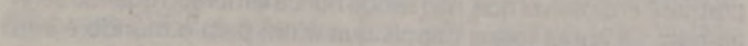

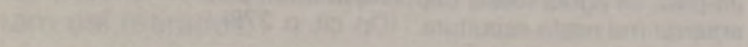

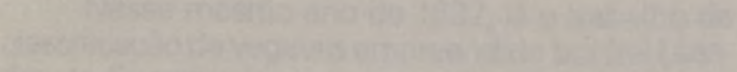

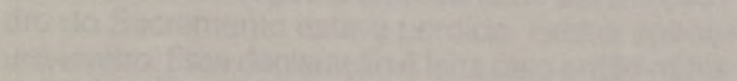

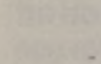

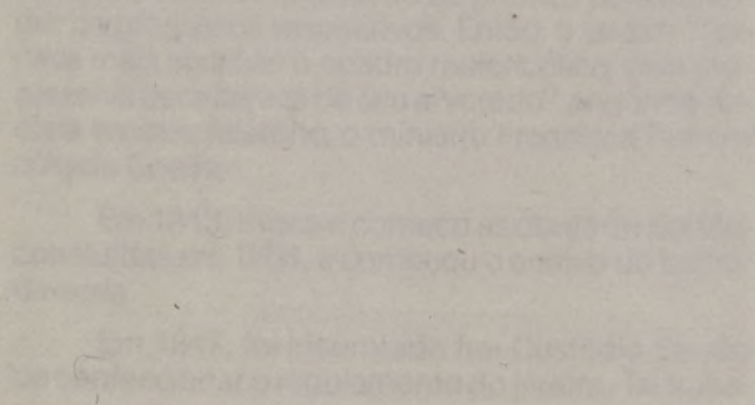

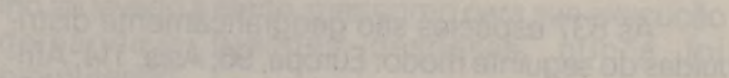

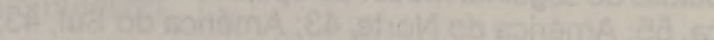

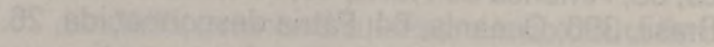

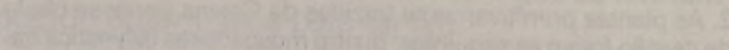

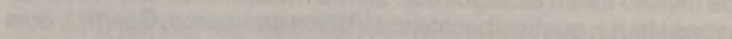

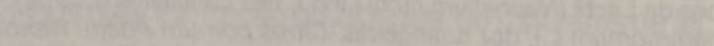

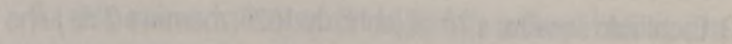

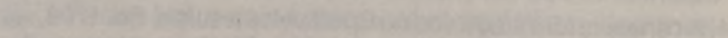

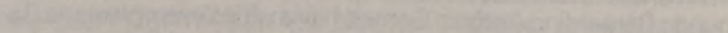

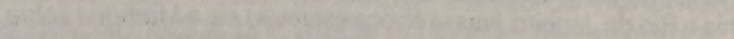
ation 14.

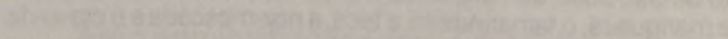

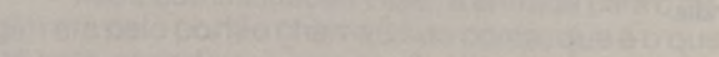

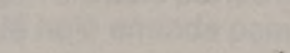

